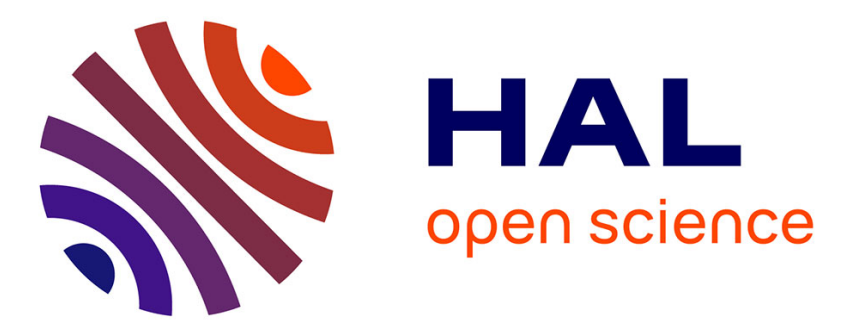

\title{
In situ high temperature oxidation analysis of Zircaloy-4 using acoustic emission coupled with thermogravimetry
}

Omar Al Haj, Véronique Peres, Eric Serris, François Grosjean, Jean Kittel, François Ropital, Michel Cournil

\section{- To cite this version:}

Omar Al Haj, Véronique Peres, Eric Serris, François Grosjean, Jean Kittel, et al.. In situ high temperature oxidation analysis of Zircaloy-4 using acoustic emission coupled with thermogravimetry. Journal of Nuclear Materials, 2015, 461, pp.365-375. 10.1016/j.jnucmat.2015.03.014 . hal-01134199

\author{
HAL Id: hal-01134199 \\ https://hal.science/hal-01134199
}

Submitted on 4 May 2015

HAL is a multi-disciplinary open access archive for the deposit and dissemination of scientific research documents, whether they are published or not. The documents may come from teaching and research institutions in France or abroad, or from public or private research centers.
L'archive ouverte pluridisciplinaire HAL, est destinée au dépôt et à la diffusion de documents scientifiques de niveau recherche, publiés ou non, émanant des établissements d'enseignement et de recherche français ou étrangers, des laboratoires publics ou privés. 


\title{
In situ high temperature oxidation analysis of Zircaloy-4 using acoustic emission coupled with thermogravimetry
}

\author{
AL HAJ Omar ${ }^{a}, \underline{\text { PERES Véronique }}{ }^{a}$, SERRIS Eric ${ }^{a}$, GROSJEAN François ${ }^{b}$, KITTEL $^{b}$ \\ Jean $^{\mathrm{b}}$, ROPITAL François $^{\mathrm{b}}$, COURNIL Michel ${ }^{\mathrm{a}}$

\footnotetext{
${ }^{a}$ Ecole Nationale Supérieure des Mines, SPIN-EMSE, PRESSIC Department, CNRS:UMR 5307, LGF, 42023 Saint-Etienne France,

${ }^{b}$ IFP Energies nouvelles, Rond-point de l'échangeur de Solaize BP3, 69360 Solaize France.
} 


\begin{abstract}
Zircaloy- 4 oxidation behavior at high temperature $\left(900^{\circ} \mathrm{C}\right)$, which can be reached in case of severe accidental situations in nuclear pressurised water reactor, was studied using acoustic emission analysis coupled with thermogravimetry. Two different atmospheres were used to study the oxidation of Zircaloy-4: a-helium and pure oxygen, b- helium and oxygen combined with slight addition of air. The experiments with $20 \%$ of oxygen confirm the dependence on oxygen anions diffusion in the oxide scale Under a mixture of oxygen and air in helium, an acceleration of the corrosion was observed due to the detrimental effect of nitrogen. The kinetic rate increased significantly after a kinetic transition (breakaway). This acceleration was accompanied by an acoustic emission activity. Most of the acoustic emission bursts were recorded after the kinetic transition (post-transition) or during the cooling of the sample. The characteristic features of the acoustic emission signals appear to be correlated with the different populations of cracks and their occurrence in the $\mathrm{ZrO}_{2}$ layer or in the $\alpha-\mathrm{Zr}(\mathrm{O})$ layer. Acoustic events were recorded during the isothermal dwell time at high temperature under air. They were associated with large cracks in the zirconia porous layer. Acoustic events were also recorded during cooling after oxidation tests both under air or oxygen. For the latter, cracks were observed in the oxygen enriched zirconium metal phase and not in the dense zirconia layer after 5 hours of oxidation.
\end{abstract}

Keywords: Thermogravimetric analysis (TGA), Acoustic Emission (AE), AE Burst, High temperature corrosion, Zircaloy-4 (Zircaloy-4) 


\section{Introduction}

Zirconium alloys are widely used as nuclear fuel cladding material, and several studies have investigated the behavior of these alloys in various high temperature oxidative atmospheres $[1,2]$. The oxidation of Zircaloy-4 at high temperature, is characterized by the growth of an inward $\mathrm{ZrO}_{2}$ layer. Thermally grown zirconia oxide scale consists of an external monoclinic layer and of a thin tetragonal layer located close to the metal/oxide interface [3]. Some authors $[1,2,3]$ have detected a variation of the kinetic rate, called breakaway, during the oxidation process of Zircaloy-4 samples under air. The growth of the $\mathrm{ZrO}_{2}$ oxide scale leads to residual stresses, both in the metal and in particular in the oxide, due to the PillingBedworth ratio of 1.56 for the volume difference between the metal and the oxide. Previous studies have proven the presence of different types of stresses during the oxidation of Zircaloy-4 [4, 5]. These stresses have several consequences: $\mathrm{ZrO}_{2}$ layer cracks, spalling of the thick scales, metal deformation, and stabilization of the cubic crystallographic phase of zirconia [6]. Parise [4] attribute the breakaway to the oxide layer crack network which gives gases free access to the metal interface. Synchrotron X-ray diffraction (S-XRD) experiments [7-10] of samples oxidized in an autoclave have shown that oxides formed on zirconium alloys are strongly compressed. When the oxide layer thickness increases, there is a reduction in the compressive stress [11-12]. Some combinations of mechanisms are relaxing the compressive stress as mechanical factors, oxidation-induced creep and strain, or crack formation in the oxide layer. But some questions still remain unresolved mainly at high temperature which is far from the operating conditions of the nuclear plants. As an example, it is not clear at which stages cracks occur during the oxidation process. Stress relaxation by cracks in the oxide layer may generate transient elastic waves which can be recorded and analyzed using the acoustic emission system (AE). This emission can be explained by abrupt variations in the stress field. When elastic energy relaxation occurs, it generates the high frequency elastic waves $(10 \mathrm{kHz}-1200 \mathrm{kHz})$ called acoustic emission (AE) [13]. Irreversible processes, such as local plastic deformations or cracks, produce AE signals during high temperature corrosion. One of the most important advantages of investigating acoustic emission is that the frequency of the signals is much higher than the frequency of the environment noise as machine vibrations or human interventions. Acoustic emission also represents an in-situ and a non-destructive monitoring method. It can be implemented on industrial equipment at a moderate cost, but it is important to adapt the AE devices to the 
industrial environmental conditions, particularly at high temperature under corrosive environments [14].

In this study an innovative device was used, based on TGA analysis coupled with acoustic emission. Sample mass variation and AE signals were recorded during oxidation of a zirconium alloy, Zircaloy-4, at $900{ }^{\circ} \mathrm{C}$. Simultaneous measurements of the two parameters, mass variation and $\mathrm{AE}$ burst, combined with post mortem characterization of oxidized samples, provided additional information on the Zircaloy-4 corrosion mechanism.

\section{Experimental}

The experiments were performed on Zircaloy- 4 cut into coupons with dimensions of $4.8 \mathrm{x}$ $4.6 \times 0.5 \mathrm{~mm}^{3}$. The chemical composition can be found in Table 1. Samples were polished and cleaned with acetone and ethanol before the oxidation tests.

Table 1

Chemical composition of Zircaloy-4 in weight \% or ppm

\begin{tabular}{|c|c|c|c|c|c|c|c|}
\hline Sn (wt\%) & Fe (wt\%) & O (wt \%) & Cr (wt\%) & C (wt ppm) & Nb (wt ppm) & H (wt ppm) & Zr \\
\hline $1.32-1.35$ & 0.21 & $0.123-0.129$ & 0.11 & $125-140$ & $<40$ & $<3$ & Bal. \\
\hline
\end{tabular}

Thermogravimetric analyses were carried out on a symmetric thermobalance (SETARAM TAG 24) with Pt-Rh 6\%/ Pt-Rh 30\% thermocouples (Figure 1), in order to measure sample mass changes during the oxidation tests with a precision of $\pm 0.001 \mathrm{mg}$. The oxidation test temperature was set at $900^{\circ} \mathrm{C} \pm 0.1^{\circ} \mathrm{C}$ and the heating rate was $15^{\circ} \mathrm{C} / \mathrm{min}$ in pure helium (Table 2). The isothermal dwell time was set at 5 hours. Once the desired temperature was reached $\left(\mathrm{T}=900^{\circ} \mathrm{C}\right)$, pure helium was changed for a mixture of $75 \% \mathrm{He}+21 \% \mathrm{O}_{2}+4 \% \mathrm{~N}_{2}$ for the first series of oxidation tests. This first gas mixture was chosen to represent an air leak in an oxygen atmosphere. An oxidant gas $\left(80 \% \mathrm{He}+20 \% \mathrm{O}_{2}\right)$ was used for the second series of oxidation tests (Table 3). In both series, the oxidant gas was introduced by mass flow meters with a total gas flow rate of $50 \mathrm{ml} / \mathrm{min}$ at atmospheric pressure. The purge time is about 7 minutes when introducing the test gas. The cooling rate was $15^{\circ} \mathrm{C} / \mathrm{min}$ under the same process gas mixture. 
Table 2

Impurity proportions (in ppm) present in $\mathrm{He}$

\begin{tabular}{|c|c|c|c|}
\hline $\mathrm{O}_{2}$ & $\mathrm{H}_{2} \mathrm{O}$ & THC $\left(\right.$ as $\left.\mathrm{CH}_{4}\right)$ & $\mathrm{N}_{2}$ \\
\hline$<1 \mathrm{ppm}$ & $<2 \mathrm{ppm}$ & $<0.5 \mathrm{ppm}$ & $<5 \mathrm{ppm}$ \\
\hline
\end{tabular}

Table 3

Data for the heating tests

\begin{tabular}{|c|c|c|c|c|c|}
\hline Test & He (\%) & $\mathrm{O}_{2}(\%)$ & $\mathbf{N}_{2}(\%)$ & Temperature $\left({ }^{\circ} \mathrm{C}\right)$ & Dwell time (h) \\
\hline 1 and 2 & 75 & 21 & 4 & 900 & 5 \\
\hline 3 and 4 & 80 & 20 & & 900 & 5 \\
\hline 5 & 80 & 20 & & 900 & 10 \\
\hline
\end{tabular}

A discontinuous acoustic emission analysis (burst analysis) is used in these tests. Burst analysis is based on acoustic emissions related to individual events occurring in a material. An AE burst starts when the signal amplitude exceeds the set threshold (this threshold may be fixed or self-adjusting to the noise level). Several parameters can be calculated from an AE burst. This study focused on the following parameters, the burst amplitude which is the maximum amplitude reached during an $\mathrm{AE}$ Burst $\left(\mathrm{dB}_{\mathrm{AE}}\right)$, the count is the number of threshold crossings during an AE Burst, the average frequency which is obtained from Count divided by Duration; it determines an average frequency over one AE Burst $(\mathrm{kHz})$.

Piezoelectric sensors enable AE signals to be recorded. They convert the mechanical waves generated during the irreversible processes into electric signals. When piezoelectric sensors are placed directly in contact with the materials, a low attenuation of the signal energy is observed [13, 14]. When sensors cannot be placed directly on the sample, for example in a high temperature environment, a waveguide may be used in order to transmit the waves from sample to sensor [15]. Different authors have mainly used alumina or platinum as waveguides $[16,17]$. These materials are characterized by a high propagation velocity, and they conserve the wave forms of the AE signals with a low attenuation of wave energy. Over the last few decades, several authors have used acoustic emission devices during studies of the high temperature corrosion behavior of metals and alloys, steel sulfidation [18], metal dusting inhibition [19], and alloy oxidation [20]. Since 1977 other authors have coupled acoustic emission with thermogravimetric analysis (TGA) in order to improve understanding of 
different high temperature corrosion phenomena [21, 22, 23, 24, 25]. The sample mass variation and the AE signals are simultaneously recorded during these experiments.

A special acoustic device (wave guide) was developed to optimize the transmission of acoustic signals from samples (AE source) to the sensors (Figure 1). The waveguide was designed in alumina to meet the following criteria: i) chemical resistance to corrosive environments (oxygen or reductive atmospheres); ii) chemical inertness with regard to the alloy samples; iii) good transmission of the acoustic signals (low attenuation of the signal energy); and iv) optimization of the contact between the sample and the waveguide. The guide's dimensions were compatible with the internal diameter of the furnace $(2 \mathrm{~cm})$ and with the thermobalance maximum load $(10 \mathrm{~g})$. Coupons were placed on the wave guide while another wave guide without specimens was placed in the reference furnace of the thermobalance in order to minimize the baseline shift during experiments and to maintain symmetry between the two parts of the thermobalance (Figure 1).

AE piezoelectric sensors were linked to the waveguide via a metallic support, and then the sensors and the metallic support were placed inside the cold part of the thermobalance where the temperature does not exceed $150^{\circ} \mathrm{C}$. The sensors were linked to an acquisition chain controlled by the AEwin ${ }^{\mathrm{TM}}$ software and results were analyzed using Noesis ${ }^{\mathrm{TM}}$ software provided by the Physical Acoustics Corporation Company. The characteristics of the acquisition chain are given in Table 4 . The threshold is very low, set at $18 \mathrm{~dB}_{\mathrm{AE}}$.

Table 4

Main characteristics of AE acquisition

\begin{tabular}{|c|c|c|c|c|c|c|}
\hline Instrumentation & Sensors & $\begin{array}{l}\text { Threshold } \\
\left(\text { dB }_{\text {AE }}\right)\end{array}$ & $\begin{array}{l}\text { System filter } \\
(\mathrm{KHz})\end{array}$ & $\begin{array}{l}\text { Model of the } \\
\text { amplifier }\end{array}$ & Sampling rate & $\begin{array}{c}\text { PDT - HDT } \\
\text { - HLT }\end{array}$ \\
\hline Characteristics & PICO 30 & 18 & $10-1200$ & $\begin{array}{l}\text { 2/4/6 gain: } \\
60 \mathrm{~dB}_{\mathrm{AE}}\end{array}$ & $\begin{array}{c}0.25 \mu s \\
(4 \mathrm{MHz})\end{array}$ & $\begin{array}{r}100-200 \\
-400(\mu s)\end{array}$ \\
\hline
\end{tabular}

Discontinuous acoustic emission analysis (AE burst) was used during this study. At ambient temperature, the normalized Hsu-Nielsen test [26] was carried out to verify the AE system. This test simulates an acoustic emission event by breaking a $0.5 \mathrm{~mm}$ pencil lead tip against the sample surface, generating an intense acoustic signal quite similar to a natural $\mathrm{AE}$ source that the sensors detect as a strong burst. Generally, the lead breaks should generate amplitudes of at least $80 \mathrm{~dB}_{\mathrm{AE}}$ for a reference voltage of $1 \mathrm{mV}$. The burst amplitude obtained 
came to $90 \mathrm{~dB}_{\mathrm{AE}}$, confirming the satisfactory transmission of acoustic signals via the waveguide at ambient temperature $\left(25^{\circ} \mathrm{C}\right)$.

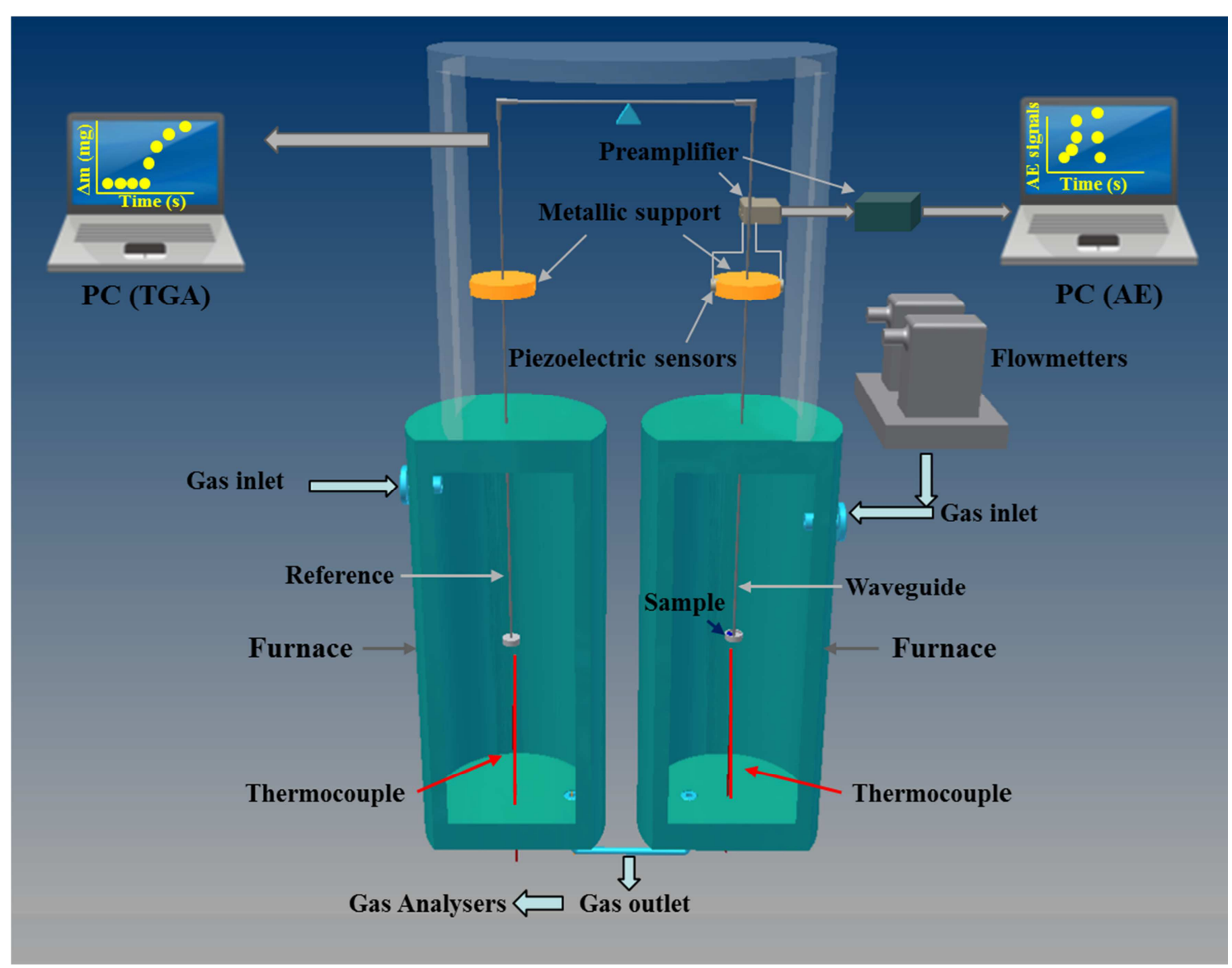

Fig. 1. Symmetric thermobalance (TGA 24) coupled with acoustic emission devices (waveguide, sensors, preamplifier)

Blank tests without any specimen at $900^{\circ} \mathrm{C}$ under air or oxygen were carried out to validate that the waveguide did not significantly react with the gas mixture. During the isothermal dwell time (Figure 2), the stability of the mass signal confirmed the chemical inertness of the waveguide and the symmetry of the experimental device. 


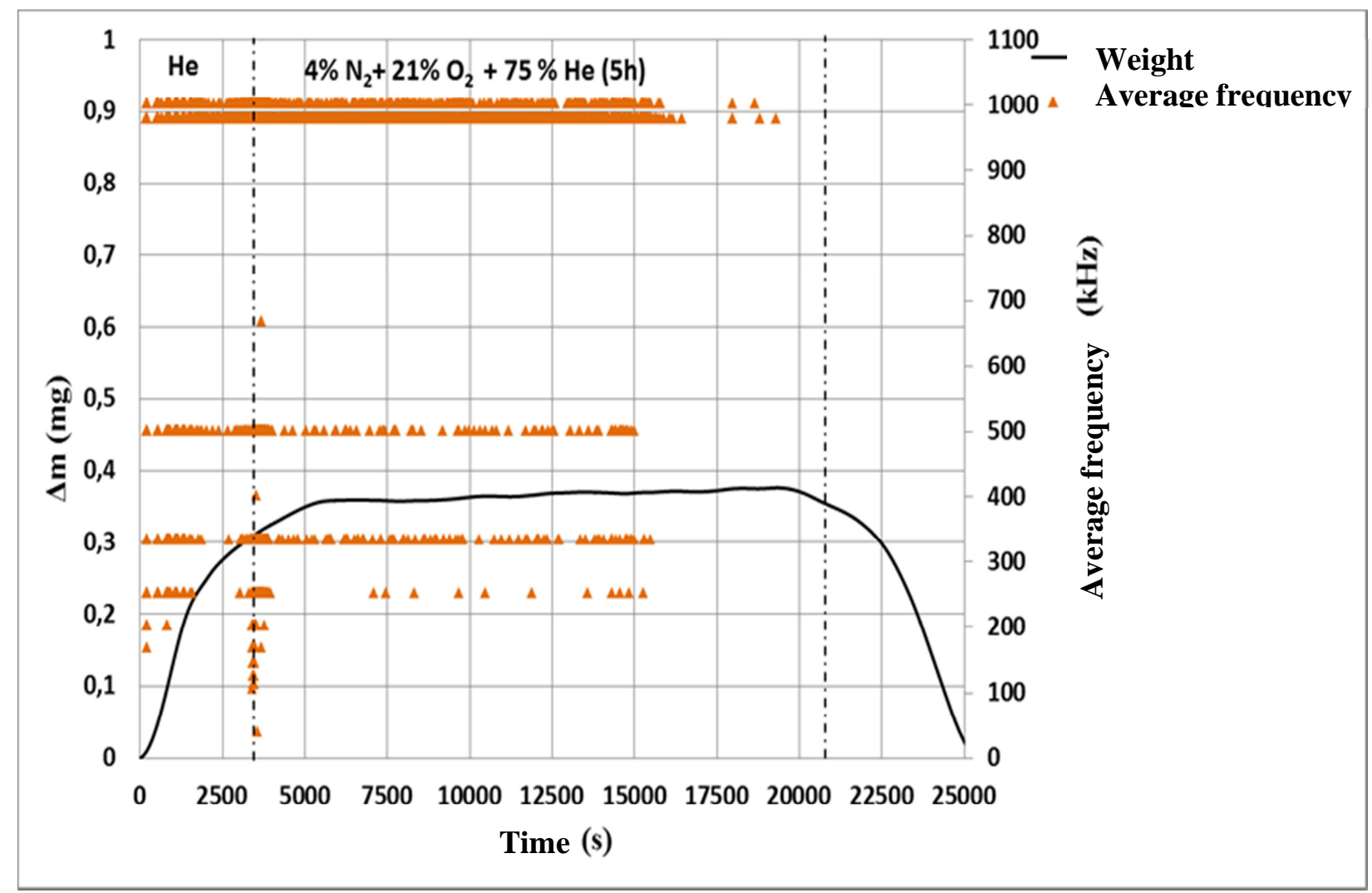

Fig. 2. Blank test without specimen at $900^{\circ} \mathrm{C}$ under air, mass gain $(\mathrm{mg})$ and average frequency of the AE bursts as a function of time

\section{Results}

\subsection{Oxidation tests under air}

\subsubsection{Thermogravimetry results}

Specimen mass variations as a function of time for corrosion tests under a mixture of helium, oxygen and air $\left(75 \% \mathrm{He}+21 \% \mathrm{O}_{2}+4 \% \mathrm{~N}_{2}\right)$ are presented in Figure 3. Although the amount of air was low in the gas mixture, these tests are named "air tests" hereafter. Rates of mass gain are presented in Figure 4. Specimen mass was normalized compared to the sample surface. The sample weight was measured before and after the oxidation test with a precision balance Mettler AG204. The ex situ measurements always confirm the TGA's mass gains. 
There was no mass variation during the heating up under pure He, while air test results show a significant increase of mass during the dwell time, with a gain of $42 \mathrm{mg} / \mathrm{cm}^{2}$ after 5 hours of oxidation. Figure 4 shows no variations in the mass gain rate during heating up, while the kinetic rate fluctuates after the introduction of the gas mixture. At the end of the test, the sample mass gain is equal to $21 \mathrm{mg}$.

An acceleration of the kinetic rate was observed $2400 \mathrm{~s}(0.66 \mathrm{~h})$ after the introduction of the oxidant gas mixture under air. This acceleration corresponds to the kinetic transition called breakaway. The breakaway is mainly explained by the appearance of cracks in the primary dense thin layer of $\mathrm{ZrO}_{2}$, giving oxygen free access to the metal oxide interface [1-6]. After the breakaway, the oxidation process is enhanced.

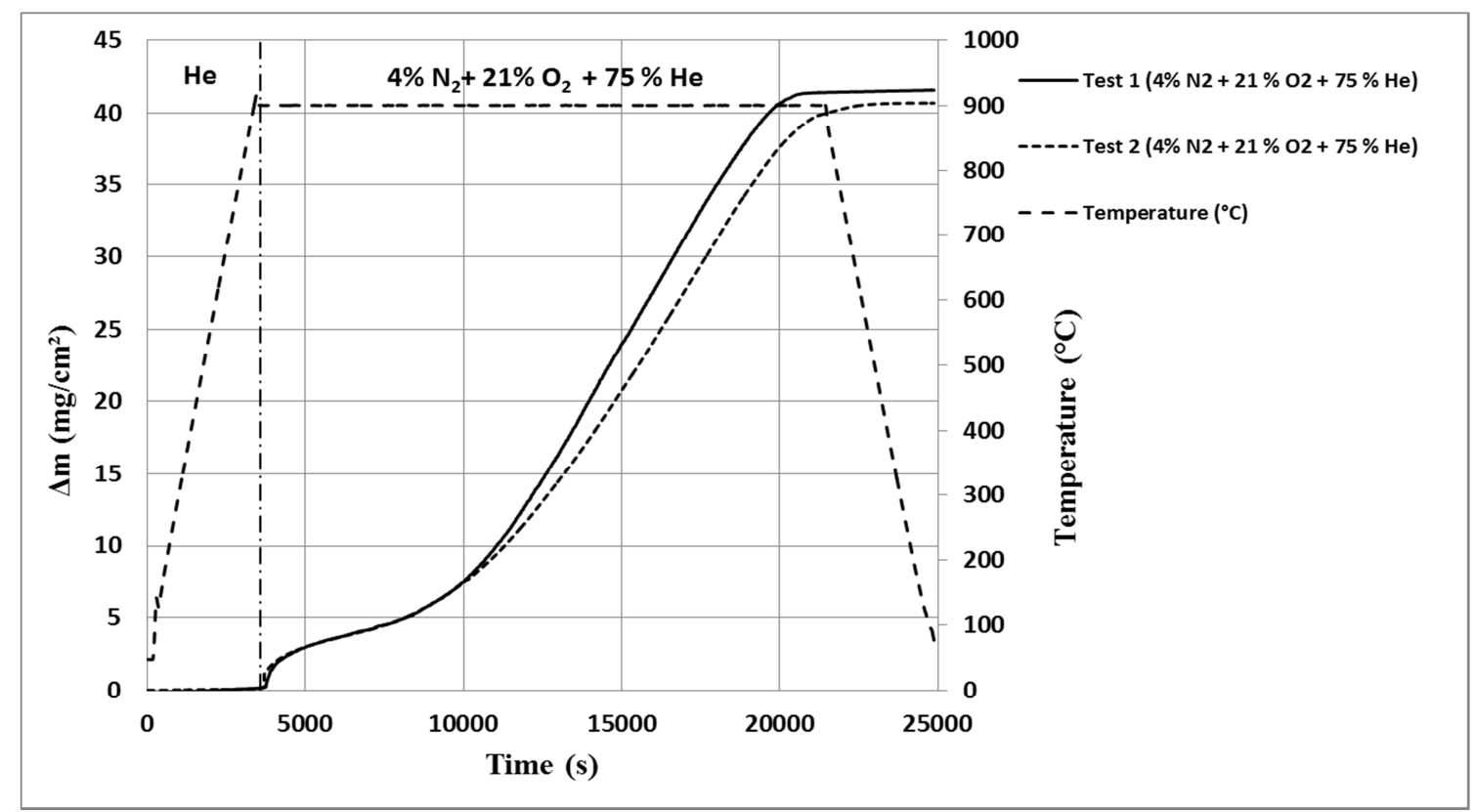

Fig. 3. Mass gain $\left(\mathrm{mg} / \mathrm{cm}^{2}\right)$ as a function of time during Zircaloy-4 oxidation tests 1 and 2 under air 


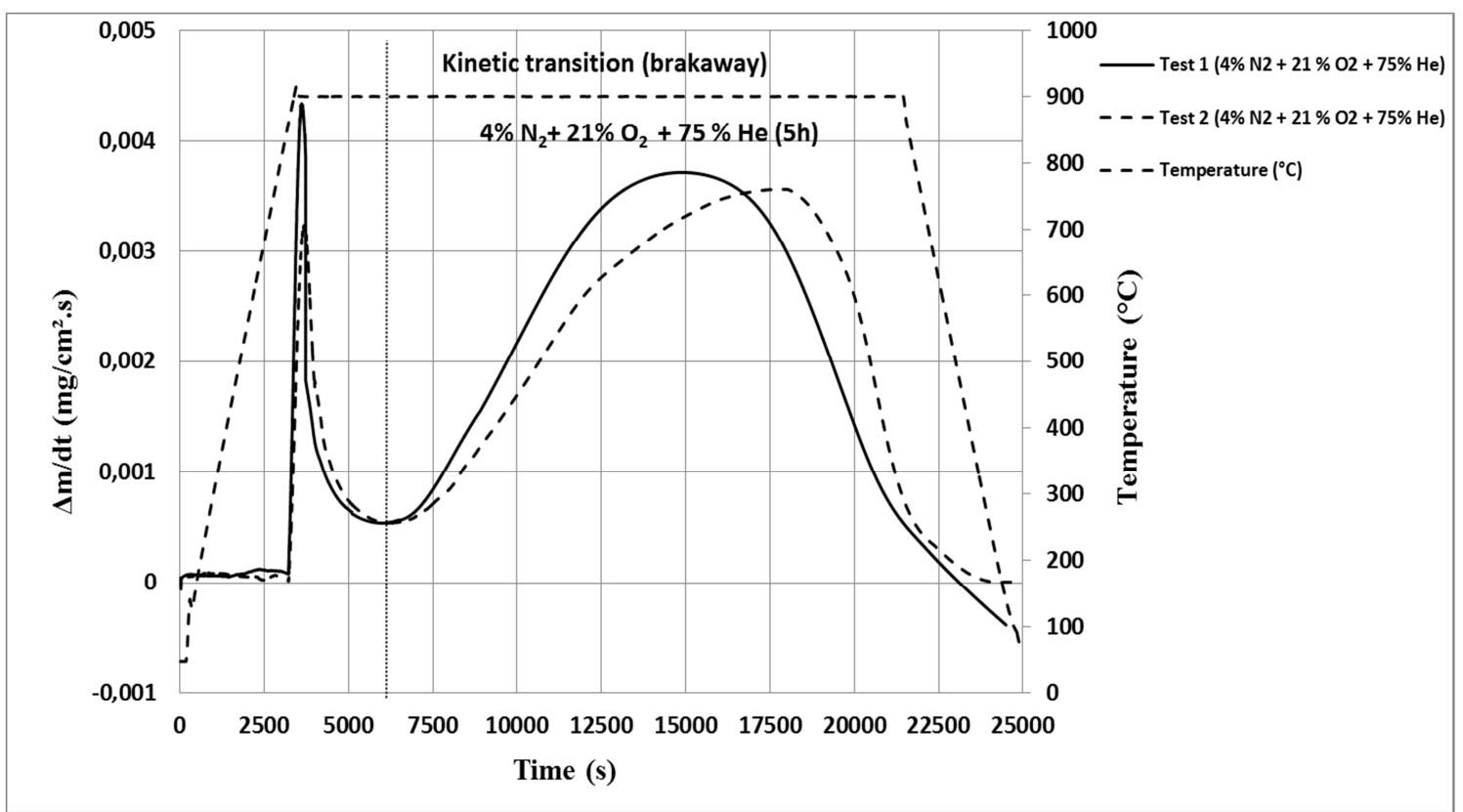

Fig. 4. Rate of mass gain $\left(\mathrm{mg} / \mathrm{cm}^{2} . \mathrm{s}\right)$ as a function of time during Zircaloy-4 oxidation tests 1 and 2 under air

The decrease of the rate of mass gain after 3 hours at high temperature is representative of the thickness of material available. The maximum corresponds to the beginning of the internal contact between the oxide scales growing from each surface of the sample; if a thicker sample had been used the process would continue.

Reproduced oxidation tests under air at $900^{\circ} \mathrm{C}$ indicate that the breakaway always occurs at the same time; the reproducibility of the rate of mass gain after the kinetic transition remains acceptable (to facilitate the reading only two curves are shown).

\subsubsection{Acoustic emission results}

Blank tests enabled the acoustic emission signals, which result from the instrumental noise (IN), to be distinguished. The characteristics of these AE signals are given in Table 5. They are characterized by a very short duration and a low number of counts, as $95 \%$ of the bursts are characterized by 1 count and a duration of $1 \mu \mathrm{s}$. They also have a high average frequency in the range of $200 \mathrm{kHz}$ to $1000 \mathrm{kHz}$ including the resonance frequency of the sensors $(300 \mathrm{kHz})$. Burst absolute energy is very low and does not exceed $0.1 \mathrm{aJ} / \mathrm{burst}$. These instrumental noise $\mathrm{AE}$ bursts were subtracted from the acoustic emission analysis for the rest of the study. 


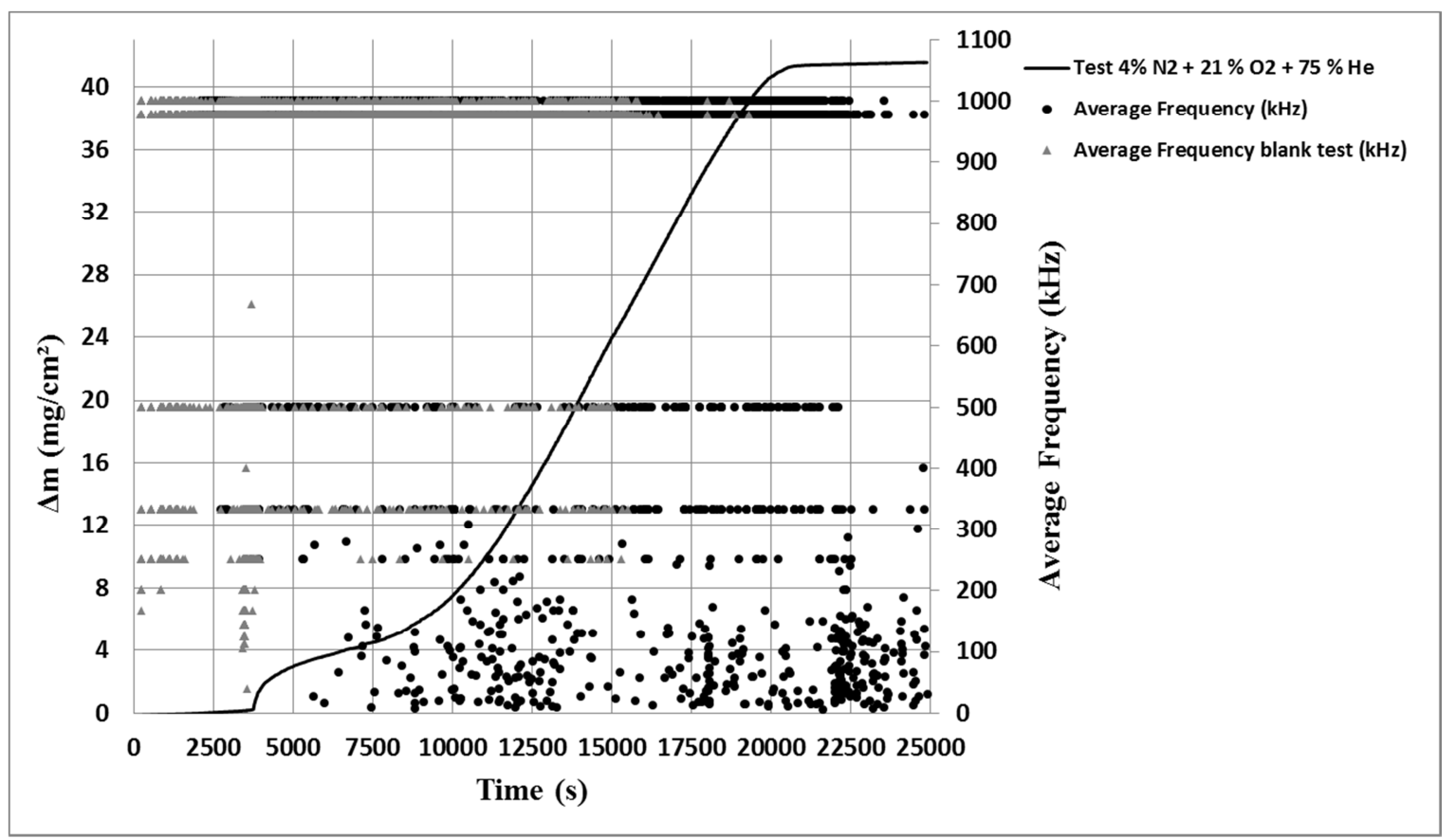

Fig. 5. ( $\Delta$ )Burst average frequency variations as a function of time for a blank test, $(\bullet)$ burst average frequency for Zircaloy-4 oxidation under air, (-) Zircaloy-4 mass gain $\left(\mathrm{mg} / \mathrm{cm}^{2}\right)$

Figure 5 presents the curve of mass gain (dark line) of Zircaloy-4 sample during oxidation tests under air. AE burst average frequencies recorded during the oxidation are black dots. AE burst average frequencies recorded for a blank test without any sample are grey triangles; they are characteristic of the instrumental noise frequencies. Some bursts recorded during the oxidation test are common with the blank test at high frequencies from 250 to $1000 \mathrm{kHz}$. AE bursts specific to the oxidized sample are characterized by a low average frequency from 0 to $200 \mathrm{kHz}$, which can be distinguished from the instrumental noise frequencies. The instrumental noise bursts have been removed from the data in the following Figures.

Figure 6 shows the burst amplitudes recorded during the oxidation tests in parallel with the kinetic rate variation as function of time. According to the kinetic rate curves, AE bursts were recorded just after the kinetic transition (breakaway) occurring $2400 \mathrm{~s}(0.66 \mathrm{~h})$ after the introduction of the oxidant gas mixture. Each time, an intense AE activity appeared just after the breakaway. These bursts, called post-transition bursts, were recorded during the temperature dwell time and are characterized by mean amplitudes in the range of 18 to $40 \mathrm{~dB}_{\mathrm{AE}}$. $\mathrm{AE}$ bursts possess a low average frequency varying between $1 \mathrm{kHz}$ to $200 \mathrm{kHz}$ with an absolute energy average of about $10 \mathrm{aJ} / \mathrm{burst}$. AE signals were also recorded during sample cooling. The bursts recorded during this cooling step were more energetic (100 aJ/burst) and characterized by long duration (1000 $\mu \mathrm{s} / \mathrm{burst}$ ), and a high count number/burst (300 counts/burst on average). AE burst characteristics can be found in Table 5 . 


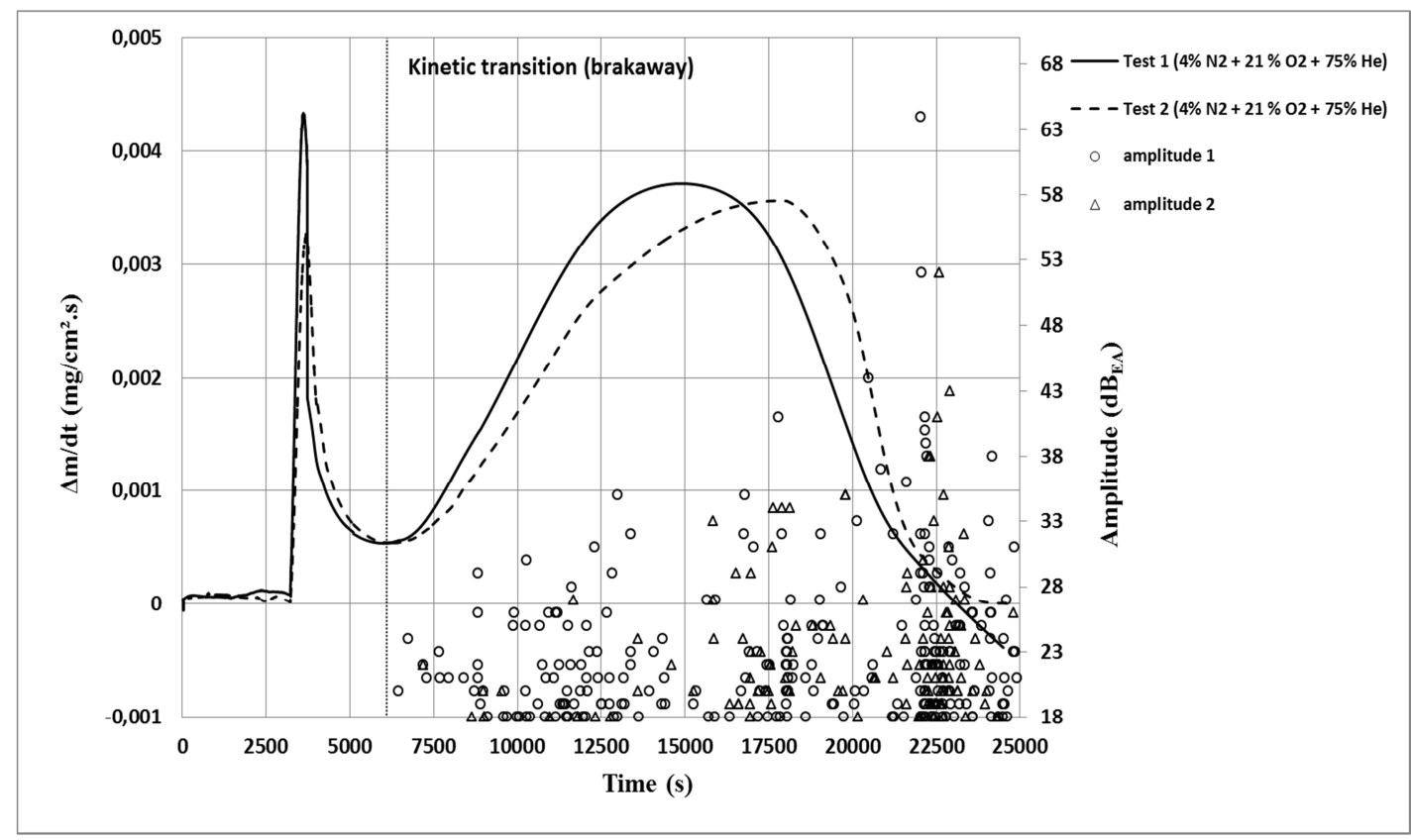

Fig. 6. Rate of mass gain and burst amplitude as a function of time during Zircaloy-4 oxidation tests under $75 \% \mathrm{He}+21 \% \mathrm{O}_{2}+4 \% \mathrm{~N}_{2}$

Table 5

Parameters of acoustic bursts recorded during blank tests and oxidation tests under air

\begin{tabular}{|c|c|c|c|c|c|}
\hline $\begin{array}{c}\text { Burst parameters } \\
\mathbf{7 5 \%} \mathrm{He}+21 \% \mathrm{O}_{2}+4 \% \\
\mathbf{N}_{2}\end{array}$ & $\begin{array}{c}\text { Amplitude } \\
\left(\mathbf{d B}_{\mathrm{AE}} /\right. \\
\text { burst })\end{array}$ & $\begin{array}{c}\text { Absolute } \\
\text { energy } \\
(\mathrm{aJ} / \text { burst })\end{array}$ & $\begin{array}{c}\text { Duration } \\
(\mu \mathrm{s} / \mathrm{burst})\end{array}$ & $\begin{array}{c}\text { Count } \\
\text { numbers/burst }\end{array}$ & $\begin{array}{c}\text { Average } \\
\text { frequency } \\
(\mathrm{kHz} / \mathrm{burst})\end{array}$ \\
\hline Blank tests & $\mathbf{1 8 - 2 0}$ & $\mathbf{0 - 0 . 0 1}$ & $1-2$ & $1-2$ & $200-1000$ \\
\hline Air test dwell time & $18-40$ & $\mathbf{0 . 0 1 - 1 0 0}$ & $2-7600$ & $2-500$ & $1-200$ \\
\hline Air test cooling & $18-64$ & $\mathbf{0 . 0 1 - 1 0 0 0}$ & $2-12500$ & $2-1500$ & $1-200$ \\
\hline
\end{tabular}

\subsubsection{Sample characterization after cooling}

The cross section of oxidized sample (Figure 7) obtained with scanning electron microscopy (JEOL $6500 \mathrm{~F}$ ) indicates that cracks are located inside the inward zirconia layer. Cracks are visible in the external dense zirconia layer (type 1), and well distributed thin convoluted cracks are observed parallel to the metal oxide interface (type 2) while big open cracks can be seen perpendicular to this interface, totally crossing the zirconia layer (type 3 ). Based on the zirconium-oxygen binary diagram [27] and on Lassere and al. observations [1], the sample core remains partially oxidized, forming an $\alpha-\mathrm{ZrO}$ solid solution of oxygen in zirconium. 


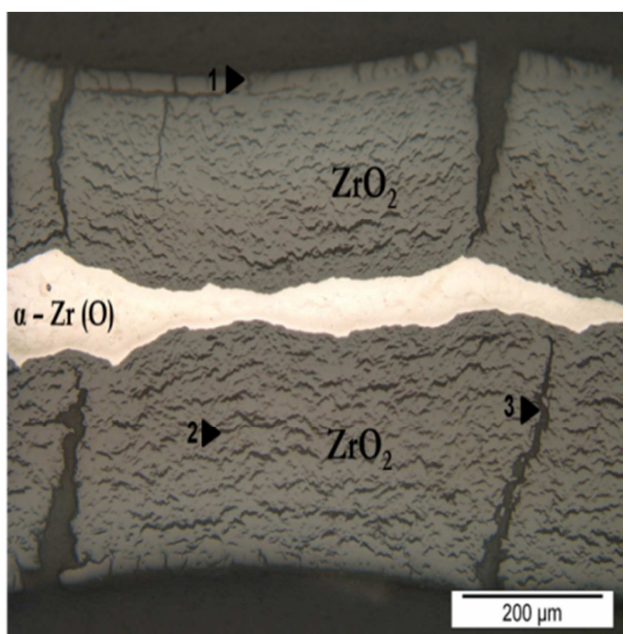

Fig. 7. SEM cross section of Zircaloy-4 oxidized under air at $900^{\circ} \mathrm{C}(\mathrm{X} 70)$

Samples were also investigated using an in-situ Raman microscope (HORIBA JOBIN YVON - XPLORA) at $900^{\circ} \mathrm{C}$ under air $\left(79 \% \mathrm{~N}_{2}+21 \% \mathrm{O}_{2}\right)$. Real time observation of sample surface evolutions was possible, and therefore identification of when sample surface cracks (type 3) appeared (Figure 8) at between 3000s (0.83 h) and 4200s (1.12 h) of dwell time, i.e. after the kinetic transition. Then the cracks grow, with micrometric thicknesses.

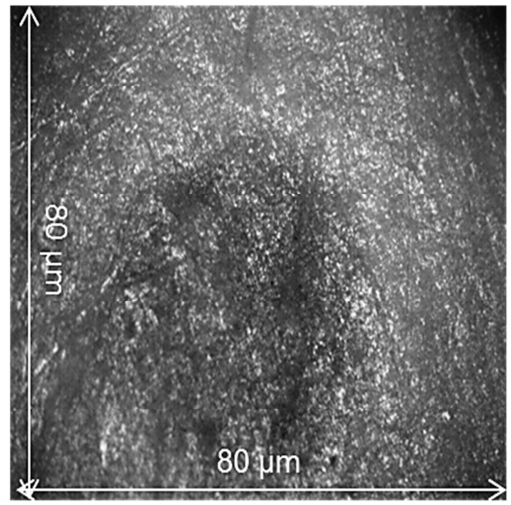

$-\mathrm{a}-$

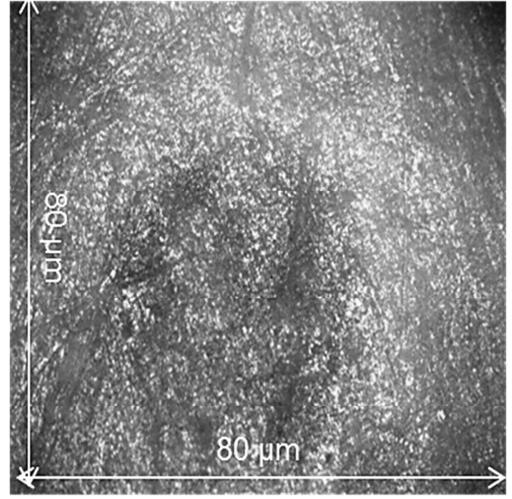

$-b-$

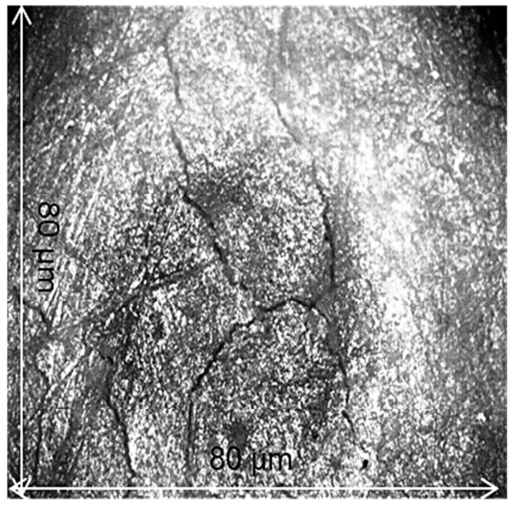

$-\mathrm{C}-$

Fig. 8. Optical microscopy observation during the oxidation of the Zircaloy-4 under air at $900^{\circ} \mathrm{C}$ : (a) 1800 seconds; (b) 3000 seconds; (c) 4200 seconds after the introduction of the oxidant gas

\subsection{Oxidation tests under oxygen}

\subsubsection{Thermogravimetry results}


In Figure 9, it can be observed that the mass gain for the oxygen tests $\left(80 \% \mathrm{He}+20 \% \mathrm{O}_{2}\right)$ is much lower than the mass variations observed for air tests. After 5 hours of oxidation the weight gain was about $8 \mathrm{mg} / \mathrm{cm}^{2}$.

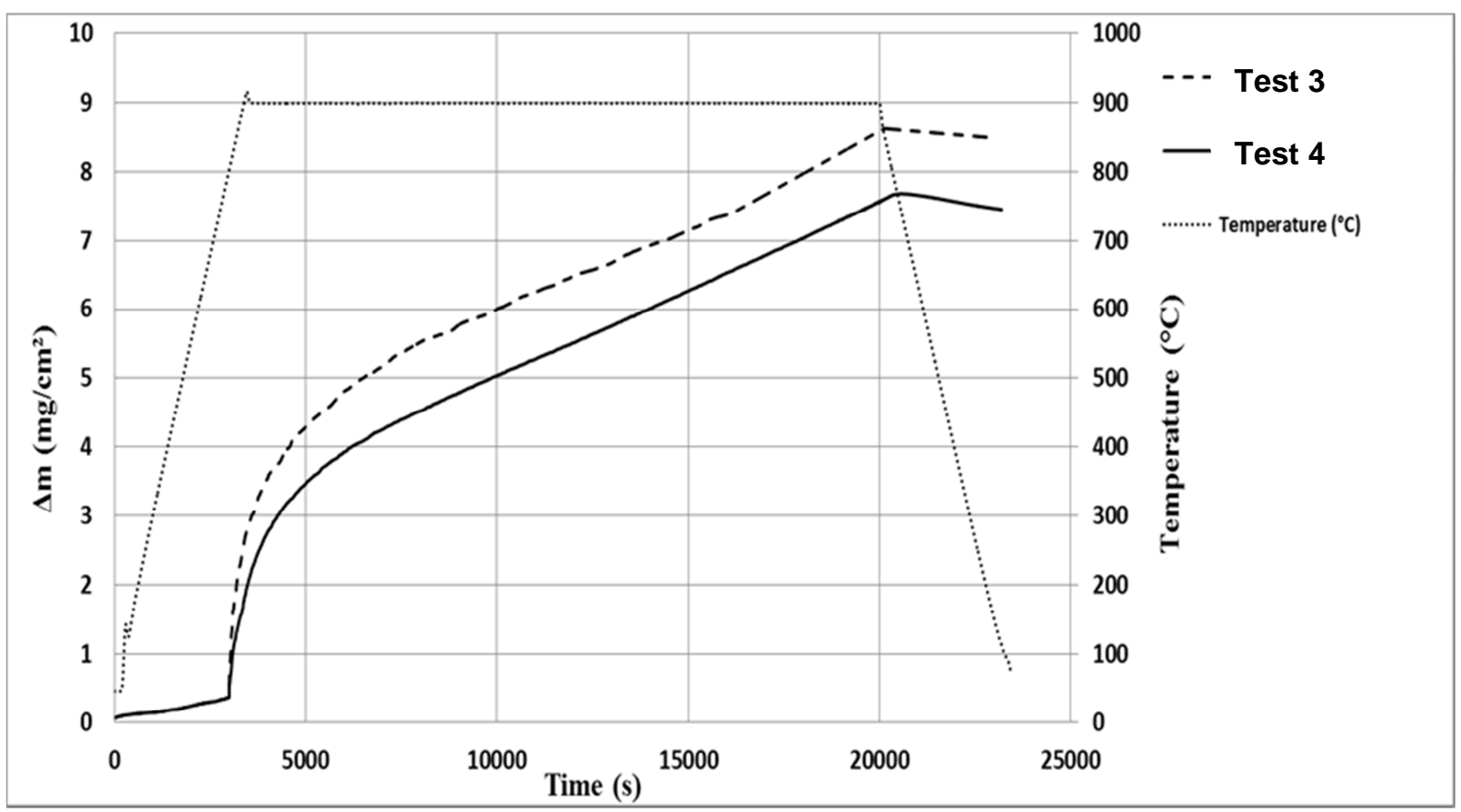

Fig. 9. Mass gain as a function of time during Zircaloy- 4 oxidation tests 3 and 4 under oxygen

The kinetic transition did not appear during the oxygen test, and the kinetic rate decreased or remained constant throughout the experiment (Figure 10). In order to confirm the absence of the kinetic transition under oxygen at $900^{\circ} \mathrm{C}$, the dwell time was extended from 5 hours to 10 hours (Figure 10). Results obtained during the extended test (10 hours dwell time) also demonstrated the absence of kinetic transition during oxidation under oxygen. The apparent mass loss of the samples during the cooling is due the gravity effect. 


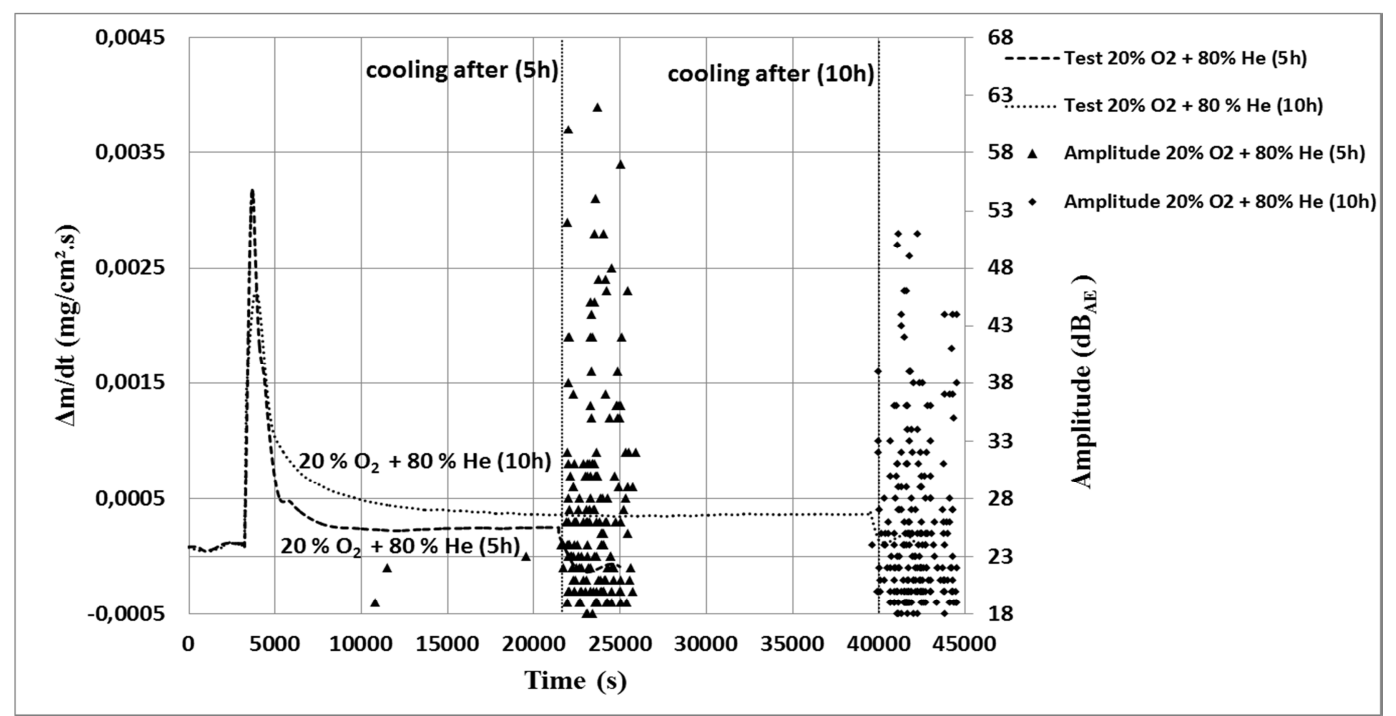

Fig.10. Rate of mass gain as a function of time and burst amplitude variations during Zircaloy-4 oxidation tests under oxygen $(\Delta)$ [5 hours] - $(\bullet)$ [10 hours]

\subsubsection{Acoustic emission results}

No AE signals (Figure 10) were observed during the dwell times. AE bursts recorded during short and extended tests under oxygen appeared only during the cooling step. The burst parameters of these tests are similar (Table 6). The AE bursts recorded during the cooling step are characterized by a high absolute energy (200 aJ/burst on average). Their count number is in the order of magnitude of hundreds of counts per burst, and their amplitude varied between $20 \mathrm{~dB}_{\mathrm{AE}}$ and $60 \mathrm{~dB}_{\mathrm{AE}}$.

Table 6

Parameters of acoustic bursts recorded during oxidation tests under oxygen

\begin{tabular}{|c|c|c|c|c|c|}
\hline $\begin{array}{c}\text { Burst parameters } \\
\text { Test } 80 \% \mathrm{He}+20 \% \mathrm{O}_{2}\end{array}$ & $\begin{array}{c}\text { Amplitude } \\
\text { (dB }{ }_{\mathrm{AE}} / \\
\text { burst) }\end{array}$ & $\begin{array}{c}\text { Absolute } \\
\text { Energy } \\
\text { (aJ/ burst) }\end{array}$ & $\begin{array}{l}\text { Duration } \\
\text { ( } \mu \mathrm{s} / \text { burst })\end{array}$ & $\begin{array}{c}\text { Count } \\
\text { numbers/burst }\end{array}$ & $\begin{array}{c}\text { Average } \\
\text { frequency } \\
\text { (kHz/burst) }\end{array}$ \\
\hline Cooling: 5 hours & $18-62$ & $0.01-10000$ & $2-15000$ & $2-2200$ & $1-200$ \\
\hline Cooling: 10 hours & $18-52$ & $0.01-2000$ & $2-15000$ & $2-1650$ & $1-200$ \\
\hline
\end{tabular}

\subsubsection{Sample characterization after cooling}

The SEM cross section of a sample oxidized under oxygen for 5 hours at $900^{\circ} \mathrm{C}$ (Figure 1 ) shows a very dense external zirconia layer. Cracks are only located in the $\alpha-\operatorname{Zr}(\mathrm{O})$ phase, which is in white contrasting with the metal phase close to the metal/oxide interface. The core 
of the sample is most probably $\alpha-\mathrm{Zr}$ which results from the transformation phase $(\beta-\mathrm{Zr} \rightarrow \alpha$ $\mathrm{Zr}$ ) occurring during the cooling step at a temperature lower than $863^{\circ} \mathrm{C}$.

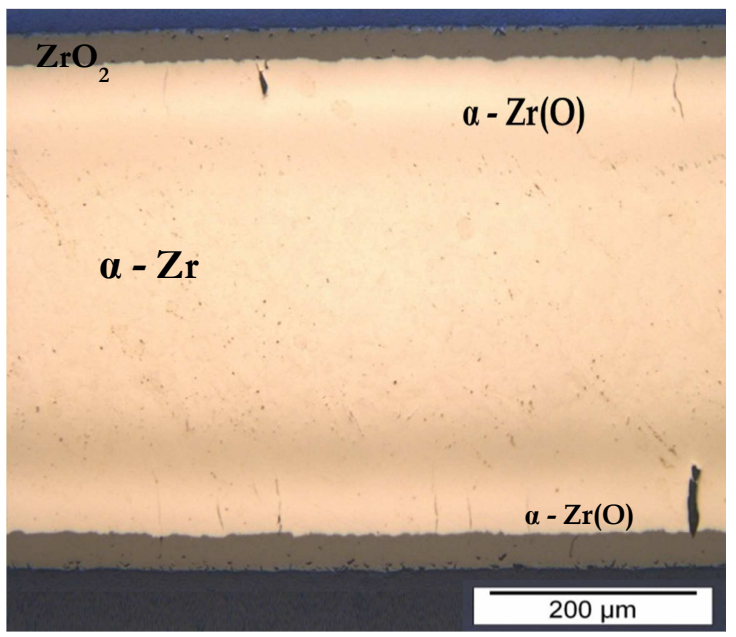

$\mathbf{a}$

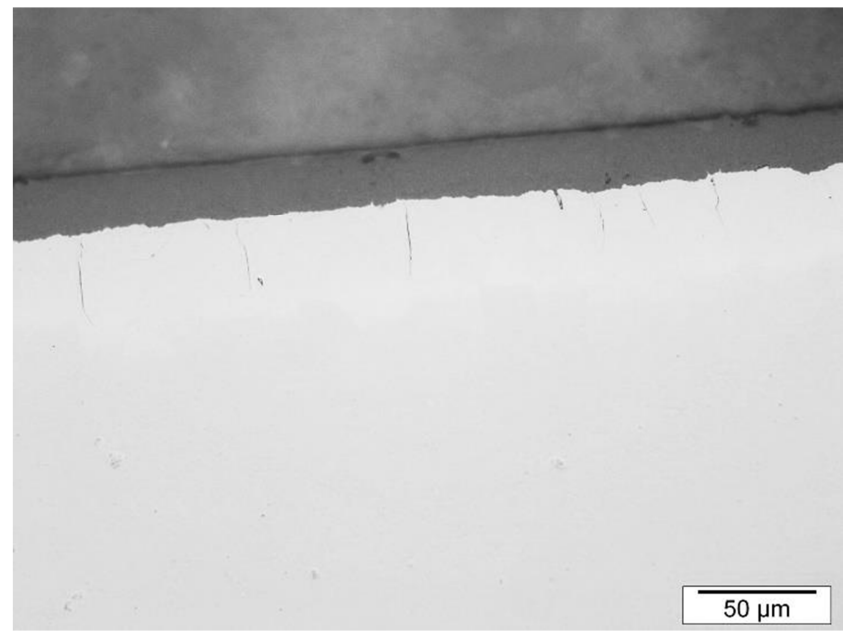

b

Fig. 11. SEM cross section of Zircaloy- 4 oxidized 5 hours under oxygen at $900^{\circ} \mathrm{C}$ a- (X100); b- (X240)

The SEM cross section of a sample oxidized under oxygen for 10 hours at $900^{\circ} \mathrm{C}$ (Figure 12) shows cracks located in the $\alpha-\operatorname{Zr}(\mathrm{O})$ phase perpendicular to the metal interface. Some of the cracks, longer ones, also cross the dense $\mathrm{ZrO}_{2}$ layer.

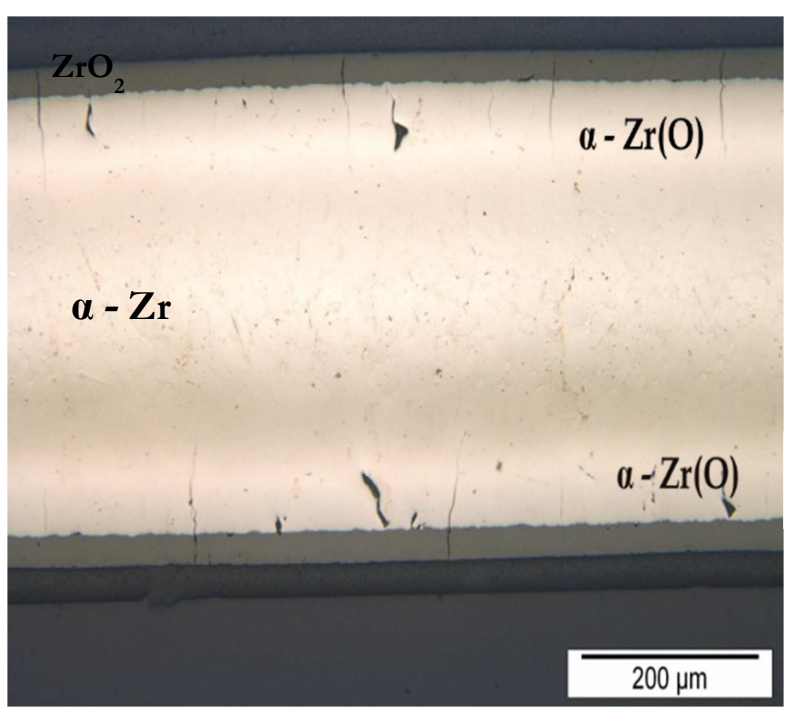

Fig. 12. SEM cross section of Zircaloy- 4 oxidized 10 hours under oxygen at $900^{\circ} \mathrm{C}$

$(\mathrm{X} 80)$

Unfortunately it was not possible to realize an in-situ Raman microscope test under helium-oxygen mixture due to a leak of the high temperature cell. 


\section{Discussion}

In the following the isothermal oxidation and the cooling are discussed.

\subsection{AE signals recorded during isothermal oxidation}

The oxidation of Zircaloy-4 at high temperature has been intensively studied during the last few decades. The oxidation mechanism under air is still under discussion, but generally it has been assumed that there are three different stages during the oxidation process: the pretransition stage, the kinetic transition and post-transition stage. During the pre-transition stage the kinetic rate follows a parabolic law, and the diffusion of oxygen vacancies in the dense protective zirconia layer is the limiting step. Then the kinetic rate reaches a minimum, followed by an increase of mass gain rate corresponding to the kinetic transition. This breakaway has been associated with the first cracks in the dense oxide layer. In our study, the kinetic transition was observed 2400 seconds after the introduction of the gas mixture under air at $900^{\circ} \mathrm{C}$. During the post-transition stage a major mass gain increase was observed. Lasserre and al. [1] have conducted kinetic oxidation studies on Zircaloy-4 at high temperature in air. They have demonstrated the effect of the nitrogen partial pressure on the oxidation rate. They have proposed a mechanism where nitrogen acts as a catalyzer during the oxidation process under air. $\mathrm{ZrN}$ precipitates were formed at the metal oxide interface, and then these precipitates were oxidized with oxygen coming from the outside. Nitrogen atoms were released which were able to react with $\mathrm{Zr}$ metal at the internal interface, again creating $\mathrm{ZrN}$ [1]. During the post-transition stage, it has been concluded that the presence of nitrogen in the atmosphere has an accelerated effect on the kinetic rate. Our results confirm the detrimental role of nitrogen which causes a rapid and a catastrophic oxidation of the Zircaloy4 at high temperature.

In case of pure oxygen at $900^{\circ} \mathrm{C}$ the oxidation of Zircaloy-4 is less critical than the oxidation under air; the oxidation has not reached the breakaway stage. The weight gain of the sample remains moderate after 5 hours at high temperature. The dense zirconia layer remains protective even after 10 hours. The breakaway may appear after a longer dwell time.

As shown by the monitoring results, AE signals were recorded during the oxidation test dwell time under air. The first acoustic signals were recorded just after the kinetic transition.

Three different types of crack (Figure 7) are present in the zirconia layer and each of them will form via a different mechanism. The formation of type 2 lateral crack may be due to interface undulations [4]. Zirconia scale growth begins with the inward formation of a dense 
$\mathrm{ZrO}_{2}$ layer at the metal-oxide interface. The Pilling-Bedworth ratio for the zirconia growth (ratio of the molar volume $\mathrm{V}\left(\mathrm{ZrO}_{2}\right) / \mathrm{V}(\mathrm{Zr})$ ) is equal to 1.56 , which means that the transformation from metal $\mathrm{Zr}$ to oxide $\mathrm{ZrO}_{2}$ induces a volume dilation. Stresses can thus be created in zirconia scale and in metal. The residual internal stresses increase in proportion to the zirconia scale thickness and once stresses exceed the fracture limit of zirconia, they can lead to cracks [5]. The mechanism for perpendicular crack formation (type 1 and 3) will be different. During oxidation after the breakaway, the perpendicular cracks in the oxide layer may be due to tensile stresses which appear at high temperature due to the elongation of the Zr metal submitted to creep.

The cracks can be associated with the $\mathrm{AE}$ signals recorded after the kinetic transition (Figure 13). The relationship between cracks and AE signals is confirmed by in-situ optical microscopy observations of oxidized samples under air. The cracks observed at the surface of the sample are in the scale of open cracks perpendicular to the metal oxide interface (type 3 in Figure 7). Some of the AE bursts can be attributed to these post-transition stage cracks. The number of type 2 convoluted lateral cracks parallel to the metal/oxide interface exceeds the amount of $\mathrm{AE}$ bursts which were recorded during the oxidation test. Thus even if the $\mathrm{AE}$ threshold is low $\left(18 \mathrm{~dB}_{\mathrm{AE}}\right)$, the energy of type 2 cracks seems to be too weak to generate recordable AE bursts.

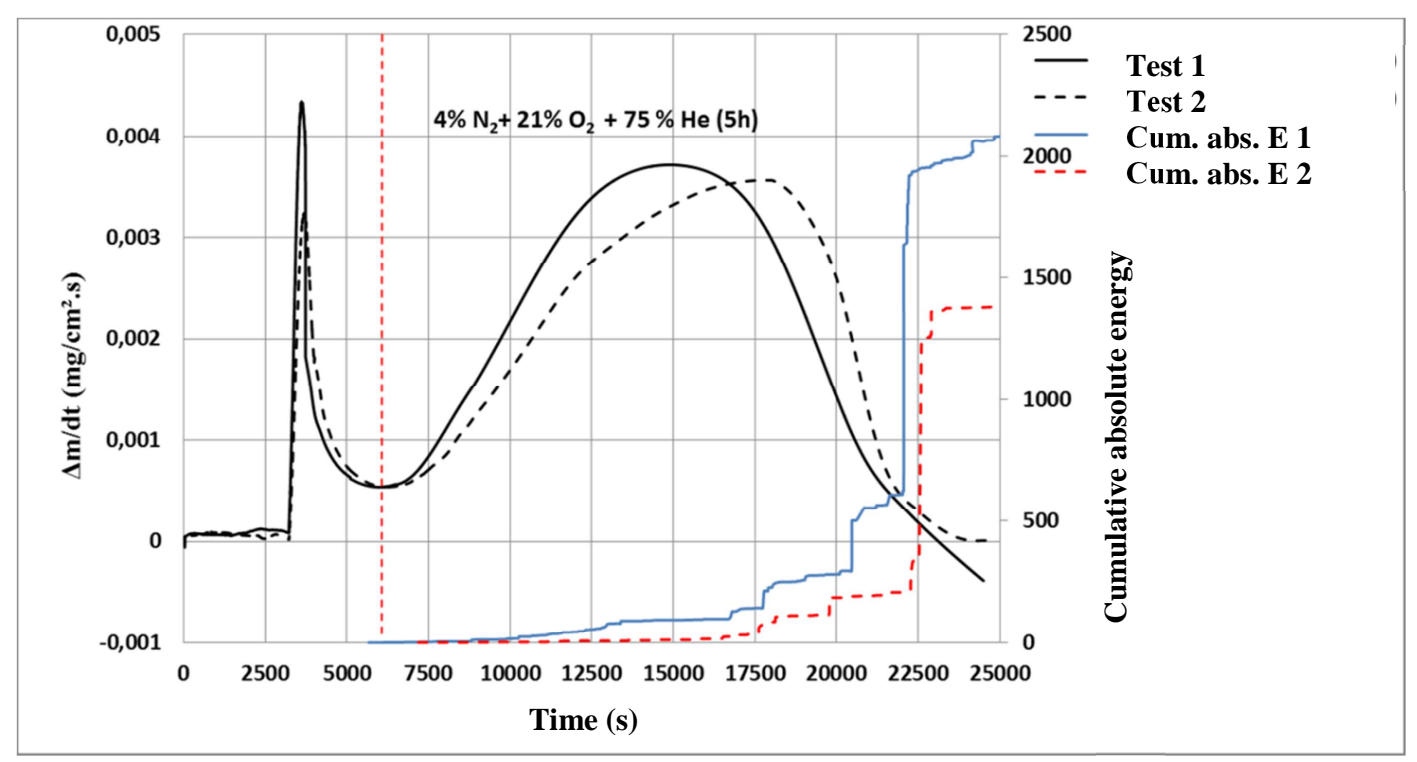

Fig. 13. Rate of mass gain as a function of time and cumulated absolute energy variations during Zircaloy-4 oxidation tests under $75 \% \mathrm{He}+21 \% \mathrm{O}_{2}+4 \% \mathrm{~N}_{2}$

\subsection{AE signals recorded during cooling}


AE signals recorded during cooling under air and under oxygen correspond to energetic processes. The parameters of the acoustic events are summarized in Table 8. Figure 14 presents the evolution of the AE cumulative counts. For both tests, a phenomenon in common appeared at the beginning of the cooling, with high AE activity occurring as the temperature decreased from $750^{\circ} \mathrm{C}$ to $700^{\circ} \mathrm{C}$. Then under air tests, AE activity remained stable during the rest of the cooling step while for oxygen tests, another major variation of AE activity appeared for temperatures lower than $400^{\circ} \mathrm{C}$. The low level of acoustic signals observed during the cooling of the samples oxidized in air may be due to stress relaxation by cracks in the oxide layer during the oxidation dwell time.

Table 8

Parameters of acoustic bursts recorded during cooling for oxidation tests under air and oxygen

\begin{tabular}{|c|c|c|c|c|}
\hline $\begin{array}{c}\text { Burst parameters } \\
\text { Cooling }\end{array}$ & $\begin{array}{c}\text { Amplitude } \\
\left(\mathbf{d B}_{\mathrm{AE}} / \text { burst }\right)\end{array}$ & $\begin{array}{c}\text { Absolute Energy } \\
(\mathbf{a J} / \text { burst })\end{array}$ & $\begin{array}{c}\text { Duration } \\
(\mu \mathrm{s} / \text { burst })\end{array}$ & $\begin{array}{c}\text { Counts } \\
\text { number/burst }\end{array}$ \\
\hline Air tests & $\mathbf{1 8 - 6 4}$ & $\mathbf{0 . 0 1 - 1 0 0 0}$ & $\mathbf{2 - 1 2 5 0 0}$ & $\mathbf{2 - 1 5 0 0}$ \\
\hline Oxygen tests & $18-62$ & $\mathbf{0 . 0 1 - 1 0 0 0 0}$ & $2-15000$ & $2-2200$ \\
\hline
\end{tabular}

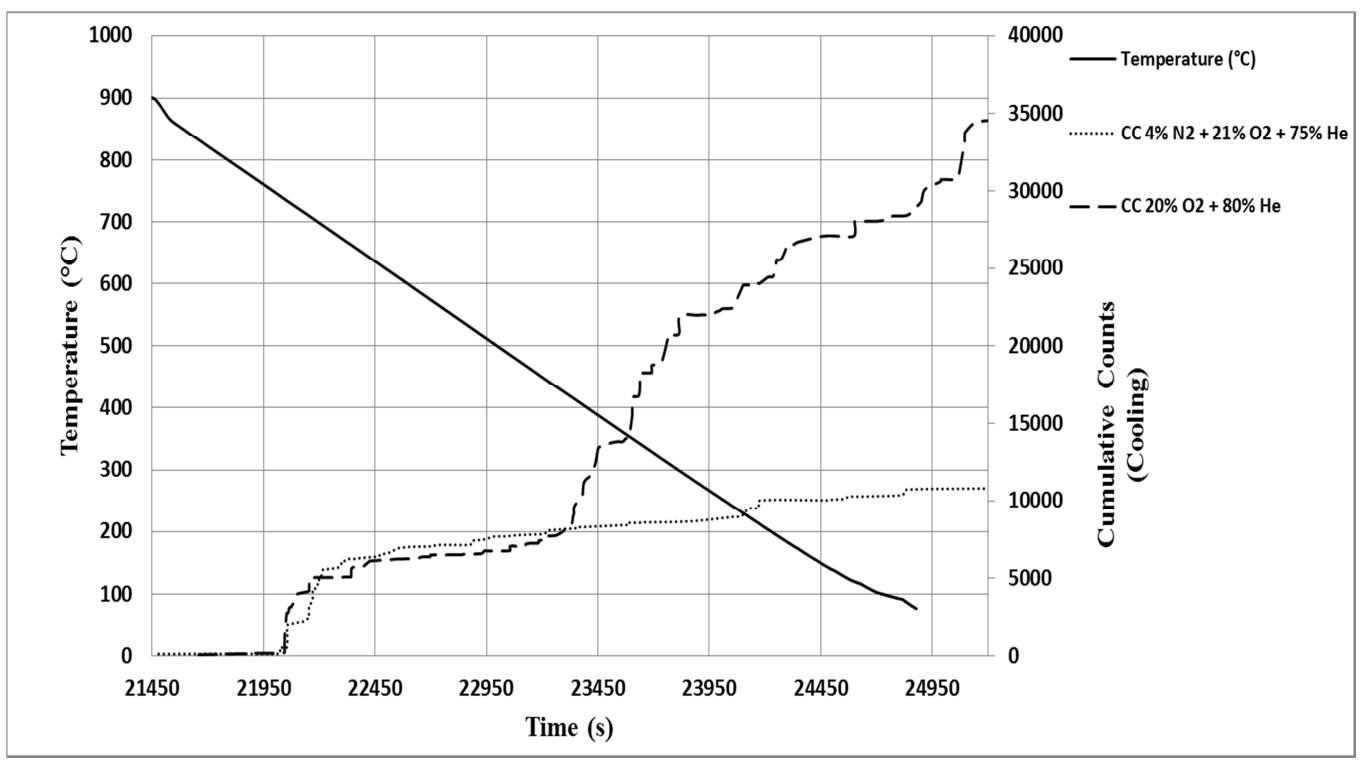

Fig. 14. Cumulated count variations as a function of time during the cooling of the Zircaloy-4 for oxidation tests under air (---) and under oxygen (-) 5 hours

To study the cooling AE signals in detail, a continuous wavelet analysis was applied to their waveforms. The wavelet transform is a mathematical tool mainly developed since the middle of the 1980s [28]. It is efficient for local analysis of non-stationary fast transient wideband signals. The wavelet transform is a mapping of a time signal to the time-scale joint 
representation and is similar to the short-time Fourier transform. The temporal aspect of the signals is preserved. The wavelet transform provides multi-resolution analysis with dilated windows. The high frequency analysis is carried out using narrow windows while the low frequency analysis uses wide windows. The bases of the wavelet transform, the wavelets, are generated from a basic wavelet function by dilations and translations. They satisfy an admissible condition so that the original signal can be reconstructed by the inverse wavelet transform. The wavelets also satisfy the regularity condition in that the wavelet coefficients decrease quickly with decreases of the scale. The wavelet transform is not only local in time but also in frequency. This analysis is directly applicable to the signal files with the Noesis software.

AE bursts recorded during the cooling under air possess a wavelet different from that of $\mathrm{AE}$ signals recorded during the cooling under oxygen at $400^{\circ} \mathrm{C}$ (Figure 15). The $\mathrm{AE}$ burst waveform for the air test is mainly one-off, with one spot line located between $280 \mathrm{kHz}$ to $420 \mathrm{kHz}$ (Figure 15.a). The AE burst waveform for the oxygen test is more continuous with two important spot lines, the first centered between $120 \mathrm{kHz}$ and $180 \mathrm{kHz}$ and the second located between $300 \mathrm{kHz}$ and $450 \mathrm{kHz}$.

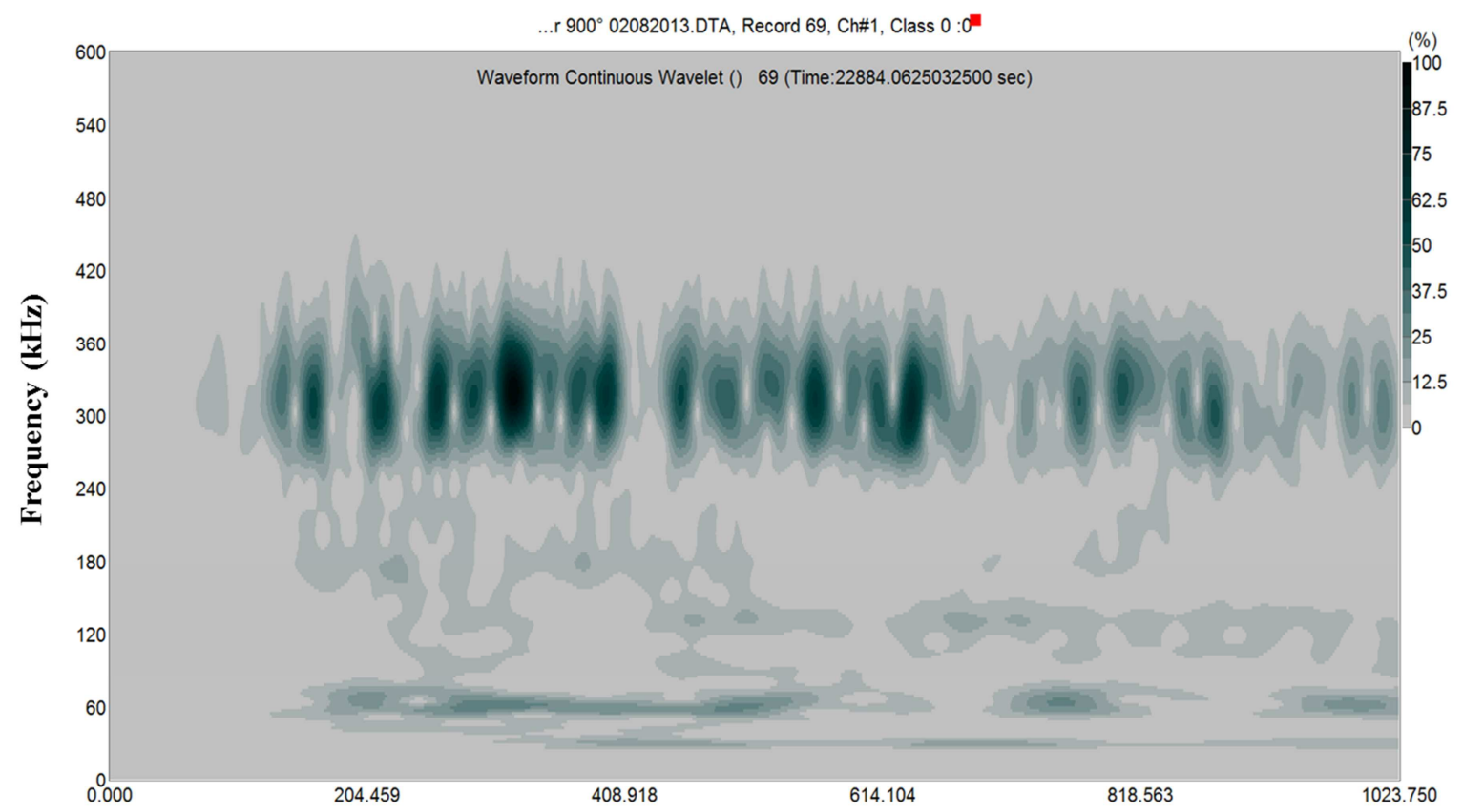

Time $(\mu s)$ 


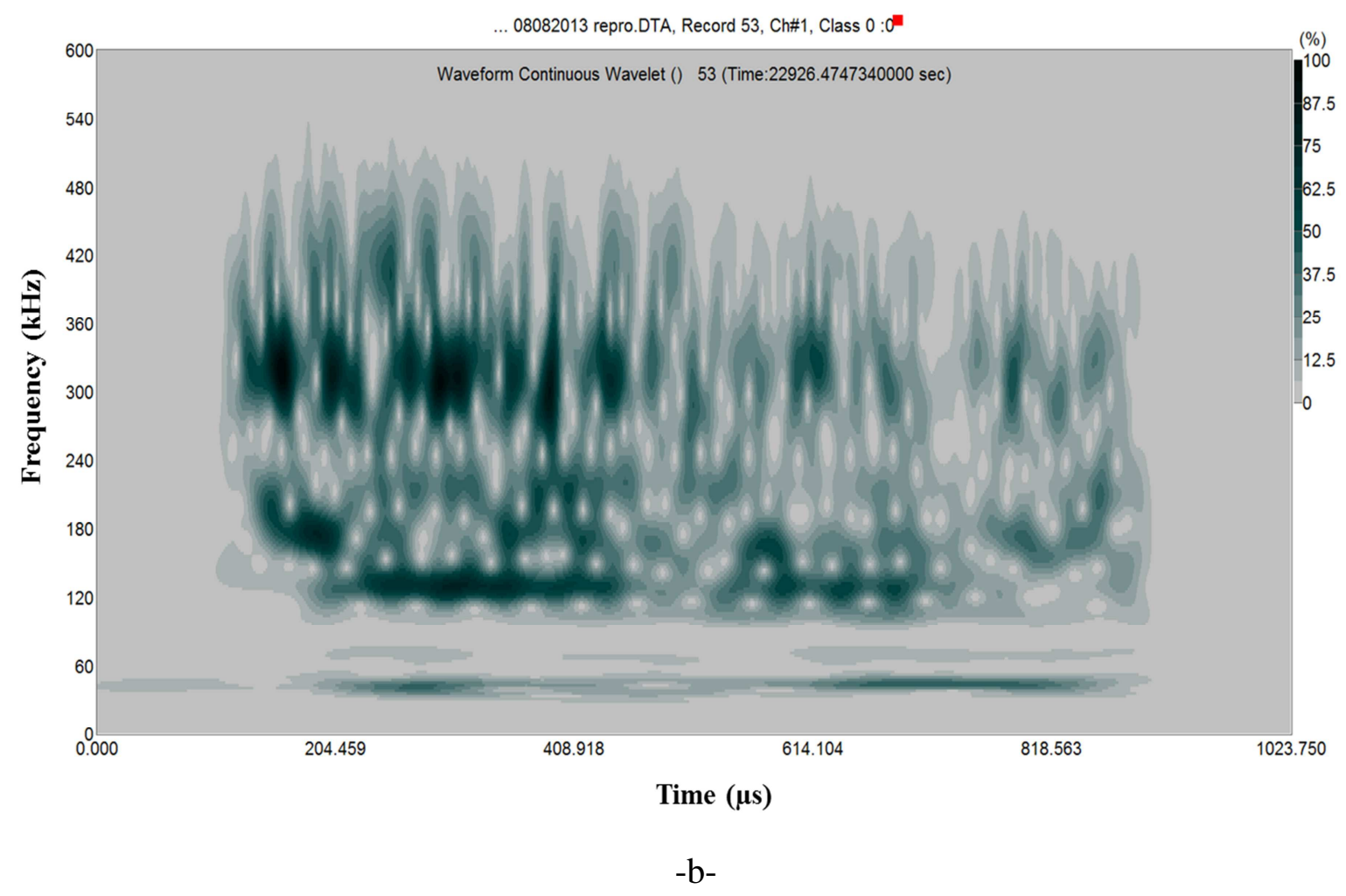

Fig. 15. Typical AE burst waveform continuous wavelets recorded during cooling of oxidation tests under air (a) at $700^{\circ} \mathrm{C}$ and under oxygen (b) at $400^{\circ} \mathrm{C}$

To further understand the cooling behavior of oxidized Zircaloy-4 samples from $900^{\circ} \mathrm{C}$ down to ambient temperature, short oxidation tests were made with differential scanning calorimetry (TGA/DSC 1 - Mettler Toledo). Heat flow variation measurements were carried out during the oxidation tests under air and under oxygen (Figure 16). The dwell time was reduced to 10 minutes in order to limit the zirconia scale thickness on the sample surface. The thermal conductivity of $\mathrm{ZrO}_{2}$ is lower than that of Zircaloy-4, so it can impact the heat flow measurement coming from the whole sample. The deformation of the coupons at high temperature could also affect the measurement as they were not in direct contact with thermocouples in the DSC balance.

The curves indicate an exothermic peak around $820^{\circ} \mathrm{C}$ for both tests. Based on the $\mathrm{Zr}-\mathrm{O}$ binary diagram, the transformation from pure $\beta-\mathrm{Zr}$ to $\alpha-\mathrm{Zr}$ occurs at $863^{\circ} \mathrm{C}$. The exothermic peak is under this reference value, it may be due to the presence of an oxide scale between the sample's metal core and the thermocouples. 


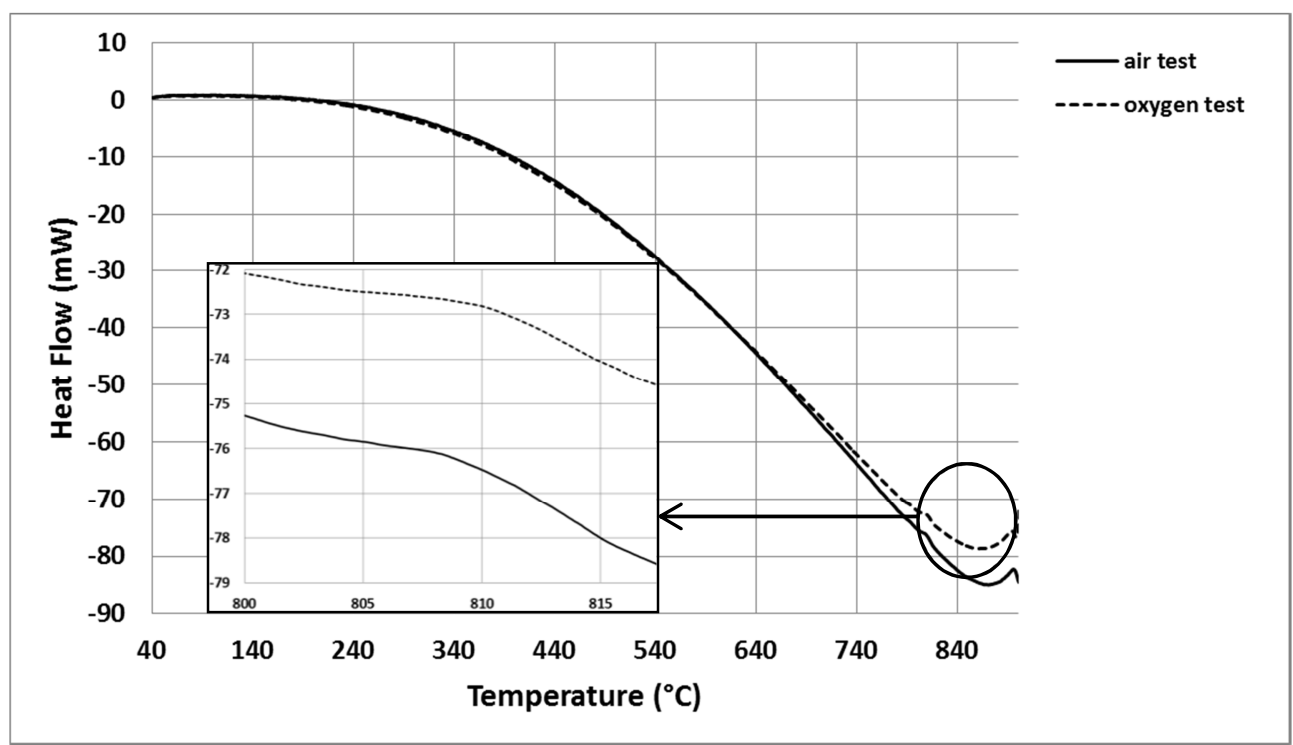

Fig. 16. Heat Flow variation as a function of temperature during cooling $\left(\mathrm{T}<900^{\circ} \mathrm{C}\right)$ under air $(-)$, and under oxygen (- - )

\section{Conclusion}

Thermogravimetric experiments coupled with acoustic emission analysis are of interest in improving understanding of metallic material corrosion at high temperature. AE analysis is complementary for post-mortem oxidized sample characterizations. The AE technique has enabled detailed study of Zircaloy-4 oxidation behavior at high temperatures. Under air tests at $900^{\circ} \mathrm{C}$, the kinetic transition is detected by a change in the mass gain rate during the isothermal dwell time. Our results confirm the detrimental role of nitrogen on Zircaloy-4 oxidation behavior at high temperatures. The breakaway stage is also immediately detected via the AE activity. AE analysis can be used to distinguish the cracks which occur during Zircaloy-4 oxidation from those which form during sample cooling. During oxidation, the cracks which appear after the breakaway are located in the $\mathrm{ZrO}_{2}$ perpendicular to the metal oxide interface. The recorded AE signals correspond to these cracks. In case of pure oxygen at $900^{\circ} \mathrm{C}$ the oxidation of Zircaloy-4 is less critical; the oxidation has not reached the breakaway stage after 10 hours. Cracks are only due to the cooling of oxidized samples. They are located in the oxygen enriched zirconium metal phase and not in the dense zirconia layer after 5 hours of oxidation. From these studies, it can be concluded that irreversible mechanisms, such as crack initiation and propagation in Zircaloy-4, generate AE signals which can be recorded simultaneously with the mass gain during the oxidation and the cooling of the sample using the innovative device TGA-AE. 


\section{Acknowledgment}

This work is part of the FUI program: IREINE (Innovation for REliability of INdustrial Equipment) dedicated to the development of devices and monitoring services to investigate the corrosion of industrial process equipment. The program is funded by the French Rhone Alpes Region.

\section{References:}

1. M. Lasserre, V. Peres, Materials and Corrosion 65, 3 (2014) 250-259.

2. M. Steinbrück, M. Böttcher, Journal of Nuclear Materials 414 (2011) 276-285.

3. I. Idarraga, M. Mermoux, C. Duriez, A. Crisci, J.P. Mardon, Journal of Nuclear Materials 421 (2012) 160-171.

4. M. Parise, O. Sicard, G. Cailletaud, Journal of nuclear materials 256 (1998) 35-46.

5. L. Kurpaska, J. Favergeon, L. Lahoche ; G. Moulin ; M. El-Marssi ; J-M. Roelandt, Oxidation of Metals, pages DOI 10.1007/s11085_012_9348_9

6. G. Schanz, S. Leistikow, Proceedings of 8th International Congress on Metallic Corrosion,» Germany, 1981.

7. N. Petigny, Journal of Nuclear Materials 280 (2000) 318-330.

8. E. Polatidis, P. Frankel, J. Wei, M. Klaus, R.J. Comstock, A. Ambard, S. Lyon, R.A.Cottis, M. Preuss, Journal of Nuclear Materials 432 (2013) 102-112.

9. H.X. Zhang, D. Fruchart, E.K. Hill, L. Ortega, Z.K. Li, J.J. Zhang, J. Sun, L. Zhou, Journal of Nuclear Materials 396 (2010) 65.

10. P. Platt, E. Polatidis, P. Frankel, M. Klaus, M. Gass, R. Howells, M. Preuss Journal of Nuclear Materials 456 (2015) 415-425.

11. P. Barberis, V. Rebeyrolle, J. Vermoyal, in: Zircon. Nucl. Ind. 15th Int. Symp. ASTM STP 1505, 2007, pp. 612-631.

12. J. Chevalier, L. Gremillard, A.V. Virkar, D.R. Clarke J. Am. Ceram. Soc., 92 (2009), p. 1901

13. D. Lockner, International Journal of Rock Mechanics and Mining Sciences \& Geomechanics Abstracts 30 (1993) 883-899.

14. K. Ono, Acoustic emission, Encyclopedia of acoustics, Wiley, (1997).

15. J. Sikorska, J. Pan, Journal Acoustic Emission, 22 (2004), 264-273.

16. M. Shuthe, A. Rahmel and M. Shütze, Oxidation of metals (1998) 33-70.

17. Y. C. Zhou, T. Hashida, International Journal of Fatigue 24, 2-4 (2002) 407-417.

18. D. Renusch, M. Schütze, Surface \& Coatings Technology 202 (2007) 740-744.

19. F. Ferrer, J. Goudiakas, E. Andres and C. Brun, Journal of Acoustic emission 18 (2000)155160.

20. M.T. Tran, M. Boinet, A. Galerie, Y. Wouters, Corrosion Science, 52 (2010) 2365-2371.

21. R.F. Hochman Proc. of the symp. On Properties of High Temperatures Alloys with Emphasis on Environnemental Effects (Eds. Z.A. Foroulis and F.S. Pettit), the Electrochemical Society (1977) 715.

22. M.J. Bennett, D.J. Buttle, P.D. Colledge, J.B. Price, C.B. Scruby and k.A. Stacey, Materials Science and Engineering, A120 199 (1989) 199-206

23. H. J. Schmutzler and H.J. Grabke, Oxidation of metals, 39 (1992) 15- 29.

24. HJ. Grabke, Materials and Corrosion; 49(1998) 303-305.

25. F. Grosjean, J. Kittel, F. Ropital, E. Serris, V. Peres, Spectra Analyse 279 (2011), 35-44.

26. European standard NF EN 1330-9 (2009)-08. 
27. J.P. Abriata, J. Garcés, R. Versaci «The O-Zr (Oxygen-Zirconium) system », Bulletin of Alloy Phase Diagrams, 7-2, (1986),116-121.

28. B. Adhemar, Mathematical Society, 2 (1995) 1-46. 